\title{
Strategi Pemasaran Usaha Pembekuan Ikan Laut Dengan Metode Matriks BCG dan SWOT Di CV. JIOEN FISHERY Di Desa Wedung, Kecamatan Brondong, Kabupaten Lamongan
}

\section{Marketing Strategy of Sea Fish Freezing Using BCG and SWOT Matrix Methods in CV. JIOEN FISHERY in Wedung Village, Brondong Subdistrict, Lamongan Regency}

\author{
Moch. Saad $^{1 *}$, Muntalim ${ }^{1}$, M. Khairul Anam ${ }^{1}$, Diena Oryza Savita ${ }^{1}$ \\ ${ }^{1}$ Fakultas Perikanan Universitas Islam Lamongan \\ Jl. Veteran No. 53 A, Lamongan \\ *Corresponding Author: muhammadsaad@unisla.ac.id
}

\begin{abstract}
ABSTRAK
Penelitian ini bertujuan untuk menentukan faktor internal dan eksternal yang mempengaruhi perusahaan, merumuskan alternatif strategi untuk meningkatkan daya saing pasar serta mengetahui strategi pemasaran menggunakan analisis BCG (Boston Consulting Group) dan analisis SWOT (Strengths, Weaknesses, Opportunities, Threats). Metode analisis yang digunakan yaitu metode penelitian deskriptif kuantitatif dengan menggunakan matrik BCG dan matrik SWOT. Hasil dari penelitian diperoleh beberapa faktor internal dan faktor eksternal yang mempengaruhi perusahaan, dari hasil matriks BCG posisi CV. Jioen Fishery berada pada posisi Bintang/ STAR sehingga strategi yang cocok untuk posisi tersebut adalah pengembangan produk, memperluas pasar dan kerja sama patungan (joint venture). Berdasarkan analisis SWOT atau kuadran SWOT, tabel IFAS dan EFAS strategi pemasaran usaha pembekuan ikan laut di CV. Jioen Fishery Desa Wedung Kecamatan Brondong Kabupaten Lamongan menggunakan strategi agresif, karena berada pada posisi kuadran I, artinya perusahaan memiliki kekuatan dan peluang yang besar.
\end{abstract}

Kata kunci: strategi pemasaran, analisis SWOT, matriks BCG, IFAS, EFAS

\begin{abstract}
This study aims to determine the internal and external factors that affect the company, formulate alternative strategies to improve market competitiveness and determine marketing strategies using the BCG analysis (Boston Consulting Group) and SWOT analysis (Strengths, Weaknesses, Opportunities, Threats). The analytical method used is quantitative descriptive research method using the BCG matrix and SWOT matrix. The results of the study obtained several internal factors and external factors that affect the company, from the results of the BCG matrix $C V$ position. Jioen Fishery is in the position of Bintang/ STAR so that the suitable strategy for that position is product development, expanding markets and joint ventures. Based on SWOT analysis or SWOT quadrants, IFAS tables and EFAS marketing strategies for sea fish freezing business in CV. Jioen Fishery, Wedung Village, Brondong Subdistrict, Lamongan Regency uses an aggressive strategy, because it is in quadrant position I, it means that the company has great strength and opportunities.
\end{abstract}

Kaywords: marketing strategy, SWOT analysis, BCG matrix, IFAS, EFAS 


\section{PENDAHULUAN}

Kabupaten Lamongan merupakan salah satu kabupaten yang ada di Jawa Timur, terletak pada bujur 6051'54" - 7023'06" Lintang Selatan dan 1120'4'41"- 112033'12" Bujur Timur, fakta tersebut dibuktikan dengan prospek pembangunan perikanan dan kelautan di Kabupaten Lamongan yang dinilai sangat cerah dan menjadi salah satu kegiatan ekonomi yang strategis. Adanya potensi laut yang luas tidak dimanfaatkan dengan baik dan diimbangi dengan penanganan yang sebaik mungkin (Yaskun dan Edi, 2017).

Menurut Ismail (2007), panfaatkan dengan baik dan diimbangi dengan penanganan pasca penangkapan dengan tepat mengakibatkan hasil tangkapan mengalami proses pembusukan dalam waktu yang cepat. Diperlukan proses penanganan dan penyimpanan yang tepat agar mutu ikan tidak mengalami kemunduran pasca penangkapan.

Salah satu tujuan perusahaan yaitu berkembang. Hal tersebut dapat dicapai melalui upaya dalam mempertahankan dan meningkatkan tingkat penjualan dalam pemasaran. Suatu perusahaan dalam proses pemasaran biasanya menggunakan strategi yang biasa dikenal dengan marketing mix atau bauran pemasaran (Kotler, 2005).

Penulis tertarik untuk melakukan penelitian menggunakan judul : "Strategi Pemasaran Usaha Pembekuan Ikan Laut dengan Metode Matriks BCG dan SWOT Di CV. JIOEN FISHERY Desa Wedung, Kecamatan Brondong, Kabupaten Lamongan”.

Berdasarkan latar belakang diatas dapat dirumuskan beberapa rumusan masalah sebagai berikut :

1. Faktor internal dan eksternal apa saja yang mempengaruhi perusahaan?

2. Strategi apa yang harus dilakukan perusahaan untuk meningkatkan daya saing pasar ?

3. Bagaimana strategi pemasaran menggunakan analisis BCG (Boston Consulting Group) dan analisis SWOT (Strengths, Weaknesses, Opportunities, Threats)?

Tujuan yang ingin dicapai sebagai berikut :

1. Menentukan faktor internal dan eksternal apa saja yang mempengaruhi perusahaan.

2. Merumuskan alternatif strategi apa yang harus dilakukan perusahaan untuk meningkatkan daya saing pasar.
3. Mengetahui strategi pemasaran menggunakan analisis BCG (Boston Consulting Group) dan analisis SWOT (Strengths, Weaknesses, Opportunities, Threats).

\section{METODE PENELITIAN}

\section{Lokasi Penelitian}

Waktu pelaksanaan penelitian ini dilaksanakan pada bulan Februari - Maret 2019. Lokasi Penelitian dilakukan di perusahaan pembekuan ikan CV. JIOEN FISHERY di Desa Wedung, Kecamatan Brondong, Kabupaten Lamongan.

\section{Metode Penentuan Sampel}

Teknik pengambilan sampel dalam penelitian ini menggunakan teknik pengambilan sampel Snowball Sampling, yaitu teknik penentuan sampel yang mula-mula jumlahnya kecil, kemudian membesar (Sugiyono, 2013). Dengan kata lain, teknik Snowball Sampling (bola salju) adalah metode sampling di mana sampel diperoleh melalui proses bergulir dari satu responden ke responden yang lainnya, biasanya metode ini digunakan untuk menjelaskan pola-pola sosial atau komunikasi (sosiometrik) suatu komunitas tertentu. Atau dengan kata lain, dalam penentuan sampel, pertama-tama di pilih satu atau dua orang, tetapi karena dengan dua orang ini belum merasa lengkap terhadap data yang di berikan, maka peneliti mencari orang lain yang di pandang lebih tahu dan dapat melengkapi data yang di berikan oleh dua orang sebelumnya. Begitu seterusnya, sehingga jumlah sampel semakin banyak.

\section{Teknik Pengumpulan Data}

Teknik pengumpulan data yang digunakan penulis dalam penelitian ini adalah data primer (data yang berasal dari wawancara langsung dengan menggunakan kuisioner) dan data sekunder (data yang berasal dari instansi, dinas, organisasi/lembaga pemerintah, pendapat para ahli, jurnal dan buku).

\section{Analisis Data}

Adapun analisis data yang digunakan dalam penelitian ini menggunakan matriks BCG (Boston Consulting Group) dan analisis SWOT. 


\section{Analisis BCG}

Menurut Noviar dan Adi (2012), analisis BCG merupakan metode yang digunakan dalam menyusun suatu perencanaan unit bisinis strategi dengan melakukan pengklasifikasian terhadap potensi keuntungan perusahaan, kemudian dimasukan ke matriks BCG secara grafis menunjukan perbedaan antara berbagai divisi dalam posisi pangsa pasar relatif dan tingkat pertumbuhan pasar.

Terdapat empat jenis produk yang dapat dibedakan tergantung pada penempatan dalam kombinasi produk pasar-pasar didalam salah satu kuadran. Matrik BCG dapat dilihat pada Gambar 1.

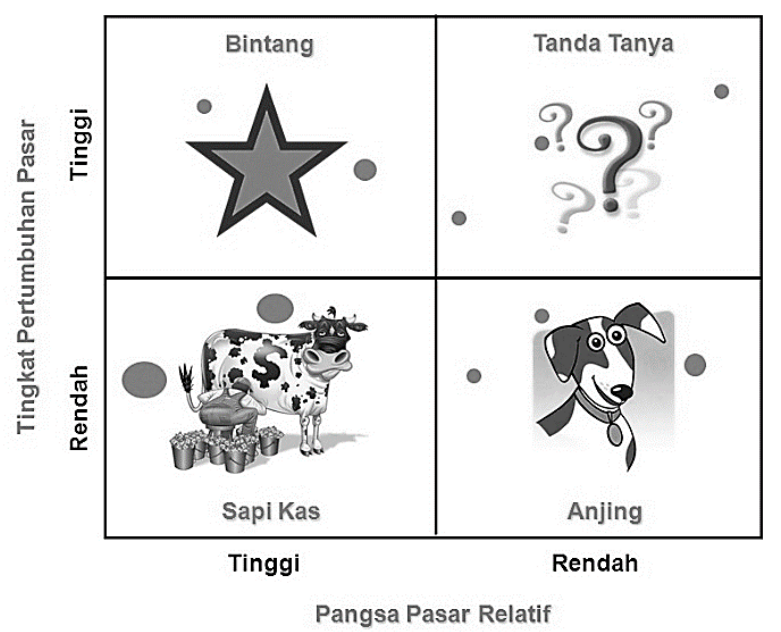

Gambar 1. Matrik BCG (Suwarsono, 2008)

Menurut Sugiyono (2014), dalam matriks BCG terdapat empat jenis produk yang dapat dibedakan tergantung pada penempatan dalam kombinasi produk pasar-pasar didalam salah satu kuadran.

- Stars atau Bintang yaitu pada sel ini memiliki peluang jangka panjang terbaik untuk pertumbuhan yang menjanjikan dan dapat menjadi salah satu sumber keuntungan bagi perusahaan.

- Cash Cow atau Sapi perah yaitu perah karena menghasilkan kas lebih dari yang dibutuhkannya.

- Question-mark atau tanda tanya mempunyai pangsa pasar yang kecil dalam suatu pasar.

- Dogs yaitu dalam kuadran ini memiliki pangsa pasar relatif rendah atau tidak tumbuh.
Tingkat Pertumbuhan pasar dapat dihitung dengan melihat pertumbuhan pendapatan rata-rata dari perusahaan :

$T P P=\frac{V P_{n}-\left(V P_{n-1}\right)}{V P-1} \times 100 \%$

dimana :

TPP = Tingkat Pertumbuhan Pasar

VPn $\quad=$ Volume Penjualan Tahun Terakhir

VPn-1 = Volume Penjualan Tahun Sebelumnya

Relative Market Share atau Pangsa Pasar Relatif dapat dihitung berdasarkan segi Pangsa Pasar ataupun segi Pendapatan :

$P P R=\frac{V P_{n}}{V P P_{n}} \times 100 \%$

dimana :

PPR = Pangsa Pasar Relatif

VPn = Volume Penjualan Tahun Terakhir

VPPn $=$ Volume Penjualan Tahun Terakhir Pesaing

\section{Analisis SWOT}

Menurut Daft (2010) menyatakan bahwa analisis SWOT (SWOT analysis) yakni mencakup upaya-upaya untuk mengenali kekuatan, kelemahan, peluang, dan ancaman yang menentukan kinerja perusahaan. Setelah faktor-faktor strategis internal suatu perusahaan diidentifikasi, suatu tabel IFAS (Internal Strategic Factors Analysis Summary) disusun untuk merumuskan faktor-faktor strategis internal tersebut dalam kerangka Strength and weakness perusahaan. Setelah faktor-faktor strategis eknternal suatu perusahaan diidentifikasi, suatu tabel EFAS (External Strategic Factors Analysis Summary) disusun untuk merumuskan faktor-faktor strategis eksternal. Analisis SWOT membandingkan antara faktor eksternal peluang (Opportunities) dan ancaman (Threats) dengan faktor internal kekuatan (Strengths) dan kelemahan (Weaknesses). Diagram analisis SWOT dapat dilihat pada Gambar 2.

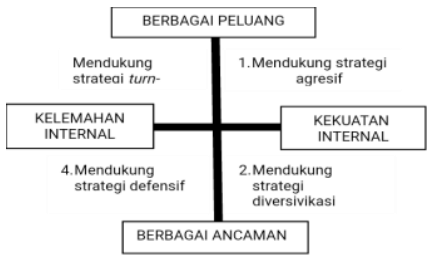

Gambar 2. Analisis SWOT 


\section{Matriks SWOT}

Alat yang dipakai untuk menyusun faktor-faktor strategis perusahaan adalah matriks SWOT. Matriks pada Tabel 1 dapat mendeskripsikan secara jelas bagaimana peluang dan ancaman eksternal yang dihadapi perusahaan dapat disesuaikan dengan kekuatan dan kelemahan yang dimilikinya.

Tabel 1. Tabel Matriks SWOT

\begin{tabular}{|c|c|c|}
\hline$x^{2}$ & STRENGTHS (S) & WEAKNESSES (W) \\
\hline EFAS & $\begin{array}{l}\text { Tentukan faktor-faktor } \\
\text { kelemahan internal }\end{array}$ & $\begin{array}{l}\text { Tentukan faktor-faktor } \\
\text { kekuatan internal }\end{array}$ \\
\hline $\begin{array}{l}\text { OPPORTUNIES }(\mathbf{O}) \\
\text { Tentukan faktor peluang eksternal }\end{array}$ & SO & WO \\
\hline THREATS (T) & & \\
\hline $\begin{array}{l}\text { Tentukan faktor } \\
\text { eksternal }\end{array}$ & ST & WT \\
\hline
\end{tabular}

\section{HASIL DAN PEMBAHASAN}

Gambaran Umum Usaha Pembekuan Ikan Segar CV. JIOEN FISHERY

Permintaan ikan segar dan beku yang cukup tinggi membuat pemilik usaha mengembangkan usahanya dengan mendirikan perusahaan di Desa Wedung pada tahun 2014. CV. JIOEN FISHERY biasanya memproduksi produk ikan beku dengan jenis ikan diantaranya adalah : Ikan Kurisi (Nemipterus japonicus) , Ikan Kerapu Sunuk (Plectropomus leopardus), Ikan Pari (Dasyatidae), Ikan Kakap Merah (Lutjanus johnii), Ikan Gulama atau Ikan Tigawaja (Nibeasoldado), Cumi-cumi (Cephalopoda), dan lain-lain.

Pendistribusian produk CV. JIOEN FISHERY mencakup wilayah dalam negeri dan luar negeri. Wilayah dalam negeri meliputi : Jakarta, Jogjakarta, Semarang, Solo, Surabaya, Mojokerto, Pasuruan, Malang dan lain-lain. Sedangkan pendistribusian produk CV. Jioen Fishery mencakup wilayah luar negeri yaitu Malaysia, China, Brunai Darusalam, Singapura, Vietnam, Abudabi dan lainlain

Bahan baku yang digunakan adalah ikan segar hasil tangkapan nelayan setempat di TPI (Tempat Pelelangan Ikan) Brondong. Bahan baku ini diperoleh langsung dari nelayan yang menjual hasil tangkapannya kepada agen-agen CV. JIOEN FISHERY.

\section{Analisis BCG}

Data yang dijelaskan dalam bab ini tidak hanya didapatkan dari tempat penelitian saja, tapi juga berasal dari sumber yang menurut peneliti diharapkan dapat mendukung dan memperkuat data.
Tabel 2 memuat daftar laporan volume penjualan produk ikan beku pada CV. JIOEN FISHERY di tahun 2017 - 2018. Tabel 2 menjelaskan bahwa total penjualan produk ikan beku CV. JIOEN FISHERY dari tahun 2017 ke tahun 2018 rata-rata mengalami kenaikan. Musim barat (bulan September-April) dan Musim Timur (bulan April- September). Tahun 2018 volume penjualan produk naik $21.401,6 \mathrm{~kg}$. Hal ini disebabkan karena perusahaan gencar melakukan promosi, tidak hanya melalui offline tetapi juga online. Era digitalisasi membuat perusahaan melakukan terobosan untuk promosi di media sosial, seperti Instagram, facebook dan juga twitter. Peningkatan kualitas produk juga menjadi faktor penting naiknya volume penjualan pada tahun 2018 . Menurut Sari et al (2015) promosi merupakan faktor penting dalam menunjang dan menaikkan volume penjualan. Bahkan faktor ini menjadi faktor kunci dalam bauran pemasaran (marketing mix) selain produk (product), harga (price) dan juga tempat (place).

Selain itu, volume penjualan produk ikan laut di CV. JIOEN FISHERY pada tahun 2018 dari bulan Januari-Desember mengalami fluktuasi bahkan ratarata mengalami penurunan (Tabel 2). Hal ini disebabkan karena adanya pesaing di wilayah tersebut yaitu CV. Suedi Jaya. Faktor pesaing merupakan faktor yang timbul di lingkungan eksternal perusahaan yang bisa menjadi ancaman bagi keberlangsungan perusahaan tersebut (Sari et $a l, 2015)$. Oleh karena itu untuk menghadapi pesaing (kompetitor), perusahaan harus mampu membuat strategi agar bisa bersaing, misalnya dengan inovasi produk, strategi harga, dan lain-lain. 
Tabel 2. Laporan Volume Penjualan Produk Ikan beku CV. Jioen Fishery Pada Tahun 2017 dan 2018

\begin{tabular}{|c|c|c|c|c|c|}
\hline \multicolumn{3}{|c|}{ Tahun 2017} & \multicolumn{3}{|c|}{ Tahun 2018} \\
\hline Bulan & $\begin{array}{c}\text { Volume } \\
\text { penjualan } \\
(\mathrm{Kg})\end{array}$ & $\begin{array}{c}\text { Presentase } \\
(\%)\end{array}$ & Bulan & $\begin{array}{c}\text { Volume } \\
\text { penjualan } \\
(\mathrm{Kg})\end{array}$ & $\begin{array}{c}\text { Presentase } \\
(\%)\end{array}$ \\
\hline Januari & $8.206,3$ & - & Januari & $6.075,8$ & - \\
\hline Februari & $8.472,8$ & 3,15 & Februari & $9.143,8$ & 33,55 \\
\hline Maret & $13.723,9$ & 38,26 & Maret & $19.688,7$ & 53,56 \\
\hline April & $16.700,3$ & 17,82 & April & $19.792,3$ & 0,52 \\
\hline Mei & $10.976,5$ & $-52,15$ & Mei & $22.824,2$ & 13,28 \\
\hline Juni & $10.338,7$ & $-6,17$ & Juni & $11.110,2$ & $-105,43$ \\
\hline Juli & $12.986,6$ & 20,39 & Juli & $12.405,8$ & 10,44 \\
\hline Agustus & $24.912,9$ & 47,87 & Agustus & $30.278,1$ & 59,03 \\
\hline September & $23.340,5$ & $-6,74$ & September & $19.609,2$ & $-54,41$ \\
\hline Oktober & $15.552,2$ & $-50,08$ & Oktober & $16.379,2$ & $-19,72$ \\
\hline November & $16.620,7$ & 6,43 & November & $11.305,6$ & $-44,88$ \\
\hline Desember & $18.576,3$ & 10,53 & Desember & $23.196,4$ & 51,26 \\
\hline$\sum$ & $180.407,7$ & 29,32 & $\sum$ & $201.809,3$ & $-2,79$ \\
\hline
\end{tabular}

- Tingkat Pertumbuhan Pasar

Tingkat pertumbuhan pasar CV. JIOEN FISHERY adalah sebagai berikut :

$$
\begin{aligned}
\mathrm{TPP} & =\frac{\mathrm{VP} n-\mathrm{VP} \mathrm{n}-1}{\mathrm{VP} \mathrm{n}-1} \times 100 \% \\
& =\frac{201.809,3-180.407,7}{180.407,7} \times 100 \% \\
& =11,9 \%
\end{aligned}
$$

Dari hasil perhitungan dapat diperoleh tingkat pertumbuhan pasar. JIOEN FISHERY sebesar 11,9\%. Menurut Rangkuti (2006) menyatakan bahwa di atas titik tengah $10 \%$ memiliki tingkat pertumbuhan pasar yang cukup tinggi.

- Pangsa Pasar Relatif

Pangsa pasar relatif CV. JIOEN FISHERY adalah sebagai berikut:

$$
\begin{aligned}
\operatorname{PRR} & =\frac{\mathrm{VPn}}{\mathrm{VPPn}} \times 100 \% \\
& =\frac{201.809,3}{126.698,6} \times 100 \% \\
& =1,6 \%
\end{aligned}
$$

Pangsa pasar relatif CV. JIOEN FISHERY sebesar $1,6 \%$, artinya pangsa pasar relatif $\mathrm{CV}$. JIOEN FISHERY relatif besar dari pangsa pasar relatif pesaing, karena menunjukkan angka lebih dari 1. Hal ini sesuai dengan buku Rangkuti (2006) yang menyatakan bahwa angka pangsa pasar telatif lebih dari 1 termasuk pangsa pasar relatif yang besar.

- Matriks BCG

Tingkat pertumbuhan pasar sebesar $13,3 \%$ dan pangsa pasar relatif sebesar 1,6\% sehingga posisi CV. JIOEN FISHERY dalam Matriks BCG dapat dilihat pada Gambar 3.

Posisi CV. JIOEN FISHERY berada pada posisi bintang (star). Ini artinya CV. JIOEN FISHERY merupakan pimpinan pasar dalam pasar yang tumbuh cepat. Menggambarkan bisnis yang berada pada tingkat pertumbuhan pasar yang tinggi dan pangsa pasar relatif yang besar.

Selain itu perusahaaan memiliki peluang jangka panjang terbaik untuk pertumbuhan dan profitabilitas bagi perusahaan. Perusahaan sebaiknya memanfaatkan kesempatan untuk tumbuh dan menghasilkan laba yang tinggi. Menambah investasi terhadap perusahaan sangatlah penting sehingga memperkuat posisi dominannya didalam pasar yang sedang tumbuh. Strategi yang cocok untuk posisi tersebut adalah pengembangan produk, memperluas pasar dan kerja sama patungan (joint venture).

\section{Analisis SWOT}

Langkah pertama tahap analisa terhadap faktor-faktor kekuatan (strenghts) dan kelemahan (weaknesses) CV. JIOEN FISHERY Fishery adalah dengan melakukan analisa melalui matrik IFAS (Internal Srategic Factor Analisis Summary). 
Berikut hasil matrik faktor strategi internal (IFAS)

dapat dilihat pada Tabel 3 .

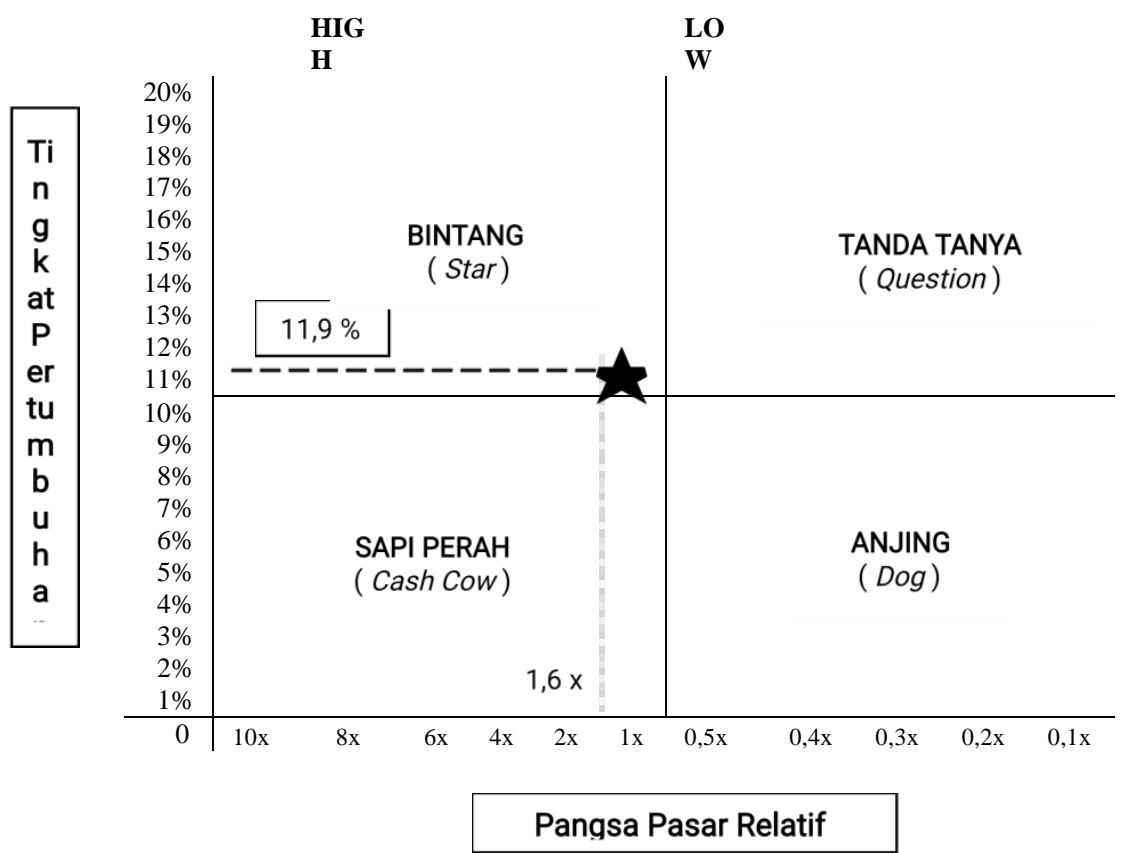

Gambar 3. Matriks BCG CV. JIOEN FISHERY (Data diolah, 2019)

Tabel 3. Matrik Faktor Strategi Internal (IFAS)

\begin{tabular}{|c|c|c|c|c|}
\hline No. & Faktor Internal & Bobot & Rating & Skor \\
\hline & KEKUATAN & & & \\
\hline 1. & Memiliki produk yang berkualitas dan berdaya saing tinggi & 0,14 & 3 & 0,42 \\
\hline 2. & Lokasi yang strategis & 0,15 & 3 & 0,45 \\
\hline 3. & Kapasitas produksi yang cukup & 0,13 & 2 & 0,26 \\
\hline 4. & Produk yang bervariatif & 0,16 & 3 & 0,48 \\
\hline \multicolumn{4}{|c|}{ Jumlah Skor } & 1,61 \\
\hline & \multicolumn{4}{|l|}{ KELEMAHAN } \\
\hline 1. & Kebersihan lokasi yang belum optimal & 0,10 & 3 & 0,3 \\
\hline 2. & Sarana dan prasarana yang terbatas & 0,13 & 4 & 0,52 \\
\hline 3. & Kurangnya media informasi sebagai sarana promosi & 0,14 & 4 & 0,56 \\
\hline \multirow[t]{4}{*}{4.} & Lahan sepenuhnya bukan kepemilikan sendiri & 0,13 & 4 & 0,52 \\
\hline & \multicolumn{3}{|l|}{ Jumlah skor } & 1,9 \\
\hline & Total IFAS & 1,00 & & 3,51 \\
\hline & Selisih IFAS & & & 2,51 \\
\hline
\end{tabular}

Pada Tabel 3 diperoleh skor total yaitu 3,51 yang dapat dikategorikan baik atau kondisi internal CV. Jioen Fishery cukup kuat. Berarti dapat dikatakan bahwa strategi internal kekuatan dan kelemahan yang dimiliki CV. JIOEN FISHERY dimungkinkan sebagai landasan perusahaan untuk melaksanakan rencana-rencana pertumbuhan dan perkembangan dalam rangka mengantisipasi tantangan kedepan.

Langkah kedua tahap analisa terhadap faktorfaktor peluang (opportunies) dan ancaman (threaths) CV. Jioen Fishery adalah dengan melakukan analisa 
melalui matrik EFAS (Eksternal Strategic Factor Analisis Summary). Berikut hasil matrik faktor strategi eksternal (EFAS) dapat dilihat pada Tabel 4.

Dapat dilihat bahwa nilai skor total adalah sebesar 3,29, sehingga dapat dikategorikan sebagai kondisi nilai yang baik. Dengan kondisi yang 'baik" menunjukan bahwa faktor-faktor eksternal perusahaan sangat terbuka lebar, dimana bahwa dapat memanfaatkan peluang-peluang yang ada dan menghindari ancaman.

Tabel 4. Matriks Faktor Eksternal (EFAS)

\begin{tabular}{|c|c|c|c|c|}
\hline No. & Faktor Eksternal & Bobot & Rating & Skor \\
\hline & PELUANG & & & \\
\hline 1. & Permintaan pasar yang terus meningkat & 0.15 & 3 & 0,45 \\
\hline 2. & Adanya perluasan pasar & 0.14 & 2 & 0,28 \\
\hline 3. & Ketersediaan bahan baku yang cukup baik & 0.16 & 3 & 0,48 \\
\hline 4. & Memiliki konsumen tetap & 0.16 & 3 & 0,48 \\
\hline \multicolumn{4}{|c|}{ Jumlah Skor } & 1,69 \\
\hline & ANCAMAN & & & \\
\hline 1. & Banyaknya pesaing yang dekat dengan tempat usaha & 0.10 & 4 & 0,40 \\
\hline 2. & Persaingan produk yang sejenis & 0.10 & 4 & 0,40 \\
\hline 3. & Pergantian musim & 0.10 & 4 & 0,40 \\
\hline 4. & Fluktuasi harga bahan baku & 0.10 & 4 & 0,40 \\
\hline \multicolumn{4}{|c|}{ Jumlah skor } & 1,6 \\
\hline & Total IFAS & \multirow{2}{*}{\multicolumn{2}{|c|}{1,00}} & 3,29 \\
\hline & Selisih IFAS & & & 2,29 \\
\hline
\end{tabular}

Tabel 5. Matriks SWOT

\begin{tabular}{|c|c|c|}
\hline \multirow[b]{2}{*}{ Faktor Eksternal } & Strengths (S) & Weaknesses (W) \\
\hline & $\begin{array}{l}\text { - Memiliki produk yang } \\
\text { berkualitas dan berdaya saing } \\
\text { tinggi } \\
\text { - Lokasi yang strategis } \\
\text { - Kapasitas produksi yang cukup } \\
\text { - Produk yang bervariatif }\end{array}$ & $\begin{array}{l}\text { - Sarana dan prasarana yang } \\
\text { terbatas } \\
\text { - Kurangnya media informasi } \\
\text { sebagai sarana promosi } \\
\text { - Lahan sepenuhnya bukan } \\
\text { kepemilikan sendiri }\end{array}$ \\
\hline Opportunies (O) & Strategi (SO) & Strategi (WO) \\
\hline $\begin{array}{l}\text { mintaan pasar yang terus } \\
\text { meningkat } \\
\text { - } \text { nya perluasan pasar } \\
\text { - } \begin{array}{l}\text { Ada } \\
\text { miliki konsumen tetap }\end{array} \\
\text { rsediaan bahan baku yang } \\
\text { cukup baik }\end{array}$ & $\begin{array}{l}\text { - Meningkatkankualitas dan } \\
\text { volume penjualan produk untuk } \\
\text { memenuhi permintaan pasar } \\
\text { - Bekerja sama dengan banyak } \\
\text { mitra untuk memenuhi } \\
\text { permintaan pasar. }\end{array}$ & $\begin{array}{l}\text { - Meningkatkan kebersihan } \\
\text { lokasi produksidan } \\
\text { meningkatkan sarana dan } \\
\text { prasarana yang ada } \\
\text { - Melakukan promosi produk } \\
\text { untuk menarik konsumen } \\
\text { baru }\end{array}$ \\
\hline
\end{tabular}




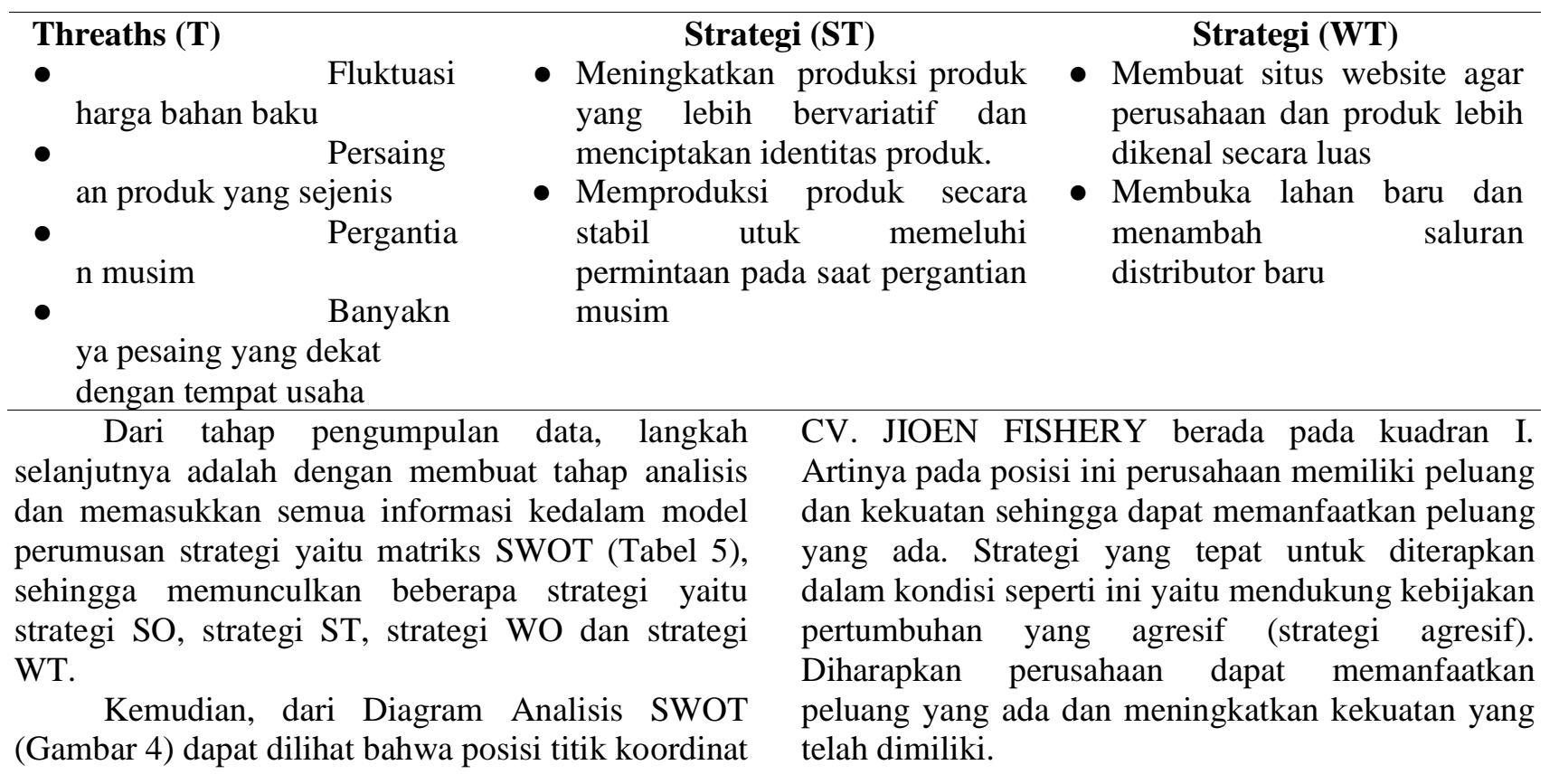

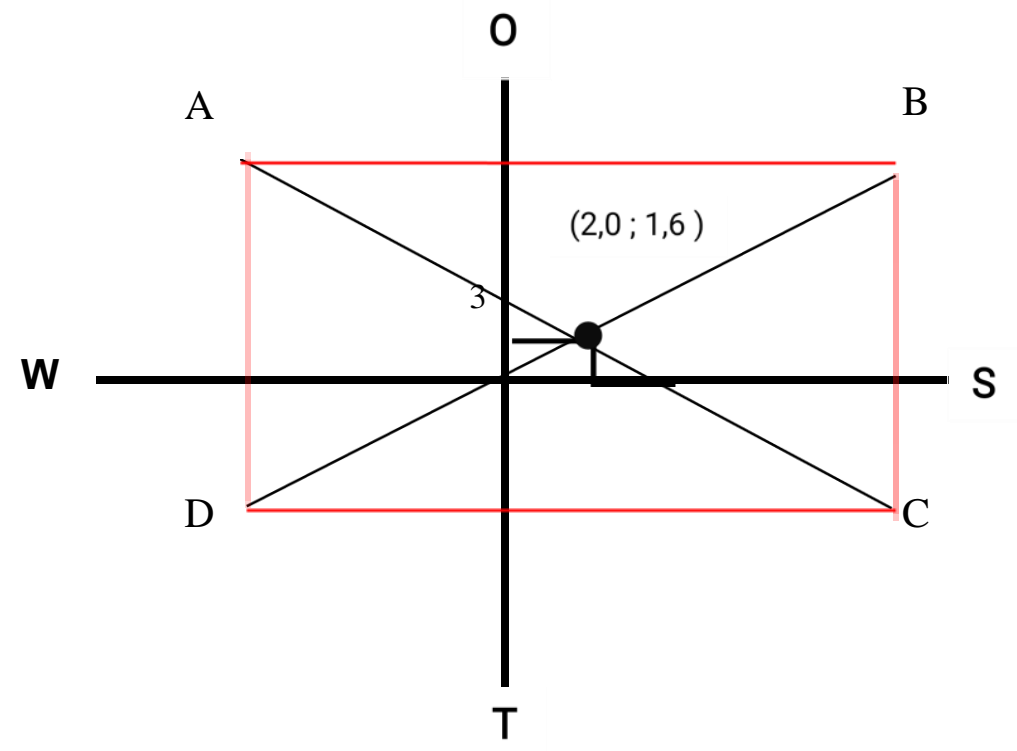

Gambar 4. Diagram Analisis SWOT

\section{KESIMPULAN}

Analisis BCG didapatkan tingkat pertumbuhan pasar sebesar $11,9 \%$, sedangkan pangsa pasar relatif diperoreh nilai sebesar 1,6\%. Artinya CV. JIOEN FISHERY berada pada posisi Kuadran II yaitu BCG STARS (pertumbuhan pasar yang sangat cepat dengan pangsa pasar yang sangat besar). Berdasarkan analisis SWOT atau kuadran
SWOT, strategi pemasaran menggunakan strategi agresif, karena berada pada posisi kuadran I.

Dari hasil tersebut maka CV. JIOEN FISHERY sebaiknya merekrut tenaga ahli dibidang manajemen pemasaran sehingga lebih memudahkan dalam menentukan strategi yang efektif untuk perusahaan, perusahaan harus lebih meningkatkan kualitas produk, dan meningkatkan promosi lewat media sosial atau internet agar jangkauan pemasaran lebih luas. 


\section{UCAPAN TERIMA KASIH}

Penulis mengucapkan terima kasih kepada CV. JOEN FISHERY Desa Wedung, Kecamatan Brondong, Kabupaten Lamongan yang telah bersedia untuk dijadikan sebagai lokasi penelitian.

\section{DAFTAR PUSTAKA}

Daft. (2010). Era Baru Manajemen. Jakarta: Salemba Empat.

Ismail. (2007). Proses Kemunduran Mutu Ikan Basah. Departemen Kelautan dan Perikanan. Akademi Perikanan Sidoarjo.

Kotler, P. (2005). Manajemen Pemasaran. Jakarta: PT. Index Gramedia.

Noviar dan Adi, M. (2012). Analisis Strategi Pemasaran Dengan Menggunakan Metode BCG (Boston Consulting Group) Pada CV. Agung Rejeki Firniture. Skripsi. Universitas Muhammadiyah Surakarta.

Rangkuti, F. (2006). Analisa SWOT Teknik Membedah Kasus Bisnis. Jakarta: PT. Gramedia Pustaka Utama.

Sari, I. A., Riniwati, H., \& Harahap, N. (2015). Strategi Pemasaran dalam Meningkatkan Volume Penjualan pada PT HATNI (Hasil Alam Tani Nelayan Indonesia) Di Desa Tlogosadang Kecamatan Paciran Kabupaten Lamongan Jawa Timur. Jurnal ECSOFiM. 3(1),16-17.

Sugiyono. (2013). Manajemen Penelitian Kualitatif Kuantitatif dan R\&D. Bandung: Alfabeta.

Sugiyono. (2014). Metode Penelitian Kuantitatif, Kualitatif, Dan R\&D. Bandung: Alfabeta.

Yaskun, M \& Edi, S. (2017). Analisis potensi hasil perikanan laut terhadap kesejahteraan para nelayan dan masyarakat di Kabupaten Lamongan. Jurnal Ekbis. 17(1), 867-868. 